\title{
Digital Platforms in the Sphere of Land Reclamation in Russia
}

\author{
Yurchenko I.F.* \\ All-Russia Research Institute of Hydraulic Engineering and \\ Reclamation by the name of A.N. Kostyakov \\ Moscow, Russia \\ e-mail: Irina.507@mail.ru
}

\author{
Bandurin M.A. \\ Kuban State Agrarian University named after I.T. Trubilin \\ Krasnodar, Russia \\ e-mail: chepura@mail.ru
}

\author{
Bandurina In.P. \\ Kuban State Agrarian University named after I.T. Trubilin \\ Krasnodar, Russia \\ e-mail: chepuraib@gmail.com
}

\begin{abstract}
In the age of the digital economy, every industry needs new infrastructure - an industry digital platform that can be used as a digital twin of an industry. According to the Russian Ministry of Agriculture, the use of specialised information platforms within the national agricultural industry increases the profitability of agricultural production by not less than $20 \%$. This is due to a targeted optimisation of expenses and an efficient allocation of funds, which increases the relevance of their use in the sphere of reclaimed agricultural production. This research aims at providing a theoretical foundation for conceptual approaches to the development of a digital platform for the reclaimed water utilisation industry. The study is novel in that it forms the principal directions for the theory and practice of creating a digital information platform for the reclaimed water utilisation industry based on the integrated technologies for solving primary tasks of agricultural production on reclaimed lands. From the practical point of view, the study is important because it systematises the existing approaches to the development of platform economy in reclamation agricultural ecosystems and creating proposals for discussion within the main directions of its evolution. The research used information, analytical, and comparative methods, as well as the method of system analysis and both statistical and expert estimates. We analysed the use of the systems for digitalising agricultural production on reclaimed lands and found the demand and the opportunity to develop the information support for the sphere of reclamation based on modern innovative technologies. The article describes the features of the digital platform offered for development. This platform will be used in the reclaimed water utilisation industry and will provide informational and technological support for the development of reclamation activities. We also assessed the predicted results and perspectives for further development of platforms in the sphere of reclamation for the Russian agricultural industry.
\end{abstract}

Keywords - digital platforms, reclaimed water utilisation industry, agricultural ecosystems, smart reclamation systems, precise management.

\section{INTRODUCTION}

According to the Russian Food Security Doctrine (2010), the timely provision of the population with quality food is an indicator of a strong state and the country's sovereignty. It's also a priority factor within the population policy and unconditional assurance for pursuing the goal of a national development strategy that is the increase of the life quality of Russian citizens by means of ensuring its high standards [1]. Land reclamation combined with the use of science-driven agricultural technologies is crucial for stable high agricultural production [2].

In the age of the digital economy, every industry needs new infrastructure - an industry digital platform that can be used as a digital twin of an industry. According to the Russian Ministry of Agriculture, the use of digital technologies in the agricultural industry based on specialised information platforms increases the profitability of agricultural production by not less than $20 \%$ due to a targeted optimisation of expenses and an efficient allocation of funds [3]

At the same time, the data of Rosstat shows that financing of ICT development in the sector of agriculture, hunting, and forestry $(0.85$ billion roubles or $0.2 \%$ of funds for the indicated area) was the lowest in comparison with other economic sectors in 2017. On the one hand, this indicates that authorities don't pay enough attention to the digitalisation of national agriculture. On the other hand, there is great potential for investments in ICT in agriculture [4]. All this makes the implementation of digital solutions in land reclamation a relative task.

This research aims at providing a theoretical foundation for conceptual approaches to the development of a digital platform for the reclaimed water utilisation industry. The platform is implemented in the form of a sub-platform within platform complexes of the Russian agricultural industry according to the Digital economy programme [5].

Main research tasks:

- analyse the development of systems for digitalising agricultural production on reclaimed lands;

- show the features of the digital platform offered for the development that will be used in the reclaimed water utilisation industry; 
- assess the predicted results and perspectives for further development of platforms in the sphere of reclamation for the Russian agricultural industry [6].

The study is novel in that it forms the principal directions for the theory and practice of creating a digital information platform for the reclaimed water utilisation industry based on the integrated technologies for solving primary tasks of agricultural production on reclaimed lands. This gives new opportunities for applying current tested knowledge as part of services provided by the digital platform based on unified, scientifically grounded solution of the most important problems of precise control over the productivity of reclaimed plant communities.

From the practical point of view, the study is important because it systematises the existing approaches to the development of the platform economy and creating proposals for discussion within the main directions of its evolution.

\section{MATERIALS AND METHODS}

The research used information, analytical, and comparative methods, as well as the method of system analysis and both statistical and expert estimates. We based our research on such scientific materials as the 'Innovative development strategy of Russia', the project of 'Industry 4.0' concept, the 'Forecast on the scientific and technical development of Russian agricultural industry', the data of Russian top technological platforms, scientific publications on the innovative development of the agricultural industry and Russia and the digitalisation of economy [8].

\section{RESEARCH QUESTIONS}

Partially controlled and self-controlled reclamation systems replaced manually controlled irrigation quite recently (about 100 years ago) [9]. Following the development of agricultural production and the necessity for its intensification, the technologies used on reclaimed lands have evolutionized from the very basic (indigenous) to highly technological methods passing through the stages of mechanisation, automation, the application of electronics and information technology [10].

In a similar way to the digitalisation of the industry and agricultural sector in Russia, the digitalisation of land reclamation sphere is associated within the science and practice of reclamation with achieving a greater potential and effect by using innovative solutions and taking optimal management decisions when turning the land reclamation sphere into a high tech sector of the economy [11]. However, we need to remember that the basis of the state economical leadership consists of fundamental science and high tech intelligent national production [12].

Nowadays, Russia imports about $90 \%$ of the hardware and $60 \%$ of software [13]. In 2015, only $12 \%$ of the technologies presented in external markets were brand new and competitive. Only $7.6 \%$ of them belonged to the sphere of production management information systems. To achieve the maximum effect from the digitalisation in the land reclamation sphere, we need the cooperation of practical experience and scientific potential that were accumulated throughout the development of the reclamation industry. We also need to use the scientific and technical advances in the digitalisation of the cutting-edge economy sectors.

The strategy of national economy digitalisation is governed by the 'Digital Economy of Russia' programme (2017) that establishes the targets and basic approaches to its development. According to the programme, the main task of digital transformation within the agricultural production is the integration of objective data flows from agricultural producers into a platform of a digital agricultural industry ensuring global planning of activities in this industry and providing a precise recommendation for market players including the use of AI, IoT, and Big Data [14].

The development of the platform economy started only recently. This type of economy uses external platforms and related ecosystems to organise the work of enterprises. The use of the platforms helps companies lower the costs and time needed to introduce new products to the market. The platform economy is economic activities that use on-line mediation and provide a platform for offering a particular product or service to clients by owners directly. We can note the methodological commonness in the functional structure of digital platforms that directly connect workers or vendors with clients and allow users to work as many hours as they want. These platforms also provide means for prompt payment after the work is done or goods are supplied [15].

Within the national scientific tradition, the term platform economy has appeared only recently. The theory of digital platforms functioning, and development needs further research. The terminology of digital platforms is still forming nowadays. It determines [16]:

- the group of technologies that comprise the basis for solving a particular specialised task of digital interaction;

- advanced innovative information system for multisided interaction of users for information and values exchange that helps to decrease the number of total transactional costs, rationalise business-processes, increase the efficiency of operations connecting the technologies for supplying goods and services [17];

- innovation infrastructure objects that allow for effective communication and creation of perspective business technologies as well as high tech, innovative, and competitive products based on the participation of all stakeholders (business, science, state, public organisations).

Provided the complexity of problems that the programme of the Russian digital economy deals with and little time for development (6 months), we can understand its criticism from the scientific community and practical specialists. This motivates us to find ways for its improvement. Currently, there is the most suitable period for making changes and amendments as the programme is going through the transformation into a national project. 
We assume that the sphere of land reclamation will gain advantages from forming the 'Reclaimed water utilisation industry' sub-platform within the platform of the Russian agricultural industry created as a part of the digital economy programme [18]. The sub-platform aims at developing and launching a software product for agricultural producers that will allow for implementing a dynamic and precise control over the reclamation regime of agricultural ecosystems as part of the basic element in resource-saving technologies in agriculture - the precise land cultivation.

The creation of the sub-platform consists of the following task:

- increasing the effectiveness of agricultural production and the turnover in the industry by means of implementing digital solutions;

- adopting high tech solutions in the agricultural sphere to minimise the negative impact of land reclamation on the environment, which is determined by ecological imperatives;

- applying principles of intelligent precise control over water resources in the agricultural ecosystems of different territorial levels to sustainably intensify crop farming;

- saving water resources, keeping the fertility and integrity of soil, creating an environmentally-friendly situation on cultivated lands;

- implementing responsible reclaimed water usage in economical, social, and ecological terms.

Besides the development of precise control over the reclamation regime of agricultural ecosystems, the 'Reclaimed water utilisation industry' sub-platform will also require the faster development of ICT features to regulate the economically viable and ecologically safe water usage including the restoration, modernisation, and development of reclamation systems. The software shell 'Reclaimed water utilisation industry' is based on the set of APIs provided by the sub-platform that also solves other digitalisation problems within the sphere of land reclamation [19].

The logic of the informational content for the functional module of the 'Reclaimed water utilisation industry' subplatform is a combination of three independent blocks [20]:

- land cultivation that ensures the preservation and reproduction of soil fertility and the production of crop growing system;

- hydrotechnical reclamation that ensures the supply of water to agricultural ecosystems in the right quantity and time;

- natural and territorial systems of different levels (geosystems and landscapes) involved in land reclamation together with mass-transfer flows, energy, information, and matter.

The accumulation of field information and obtaining control signals from IoT-platforms/applications are the tasks of peripheral devices installed in the field/on buildings. These devices include sensors, gages, attachable equipment, meteorological stations, etc. All platform components interact via different links (GPS/GLONASS, LPWAN, LTE, 3G, GPRS, GSM) [21].

The digital platform itself (a web-platform for creating industry applications for the reclaimed water usage industry) performs the function of integration, control, and monitoring of attached peripherals, storing data flows and providing the information security for the digital ecosystem.

The network principle and the principle of technological and data openness should become the basis for the digital platform. The task of ecosystems is to organise the data flows and make them secure and available for digital platforms and users. The creation of digital platforms is a dual task of developing new:

- technologies that can process large volumes of data and support global systems of storing, distributing, and processing information

- activity models based on the capabilities of these systems.

The digital platform absolutely changes the technologies themselves, organisational structures, competences, skills, and knowledge of the personnel, relations with suppliers and clients, activity models, target markets, and other areas where business interacts with people, society, and state.

Nowadays, we can't reliably estimate the proposed solutions for the development of the digital platform in the sphere of land reclamation. This is because within the agricultural industry of Russia there are no such smart platforms for controlling the supply and discharge of water for the precise reclamation of farming lands despite that these platforms play a significant role in increasing the fertility and decreasing the costs of agricultural production while making cultivated lands environmentally stable. Good examples of successful development and implementation of digital platforms for controlling water resources in agricultural production can be found in the USA (SWAMP, Smart Water Management Platform) and Uzbekistan (SUV-Info) [22].

SWAMP project represents an intelligent IoT-based platform for controlling water resources used for precise irrigation in agriculture with a practical approach (pilot projects in Brazil and Europe). The platform is embedded and used depending on the requirements and limitations in different use conditions attributed to the special features of a country, climate, soils, and crops. This requires great flexibility for adapting to the range of configurations of deployment that include various combinations of technologies.

The experience in creating and implementing SWAMP has shown that major problems that impede the broad use of IoT for precise irrigation are:

- the lack of opportunity for complete automation of irrigation software development;

- the lack of modern software platforms for automating the process for integrating technologies: IoT, Big Data, and cloud computing that ensure the deployment of 
pilot applications for the intelligent control of water resources;

- the lack of standards and information models that are necessary for the integration of different sensors into the system of control and management.

The SUV-Info conceptual digital platform for sustainable control over water resources in the countryside is still under development in Uzbekistan. The scientific and educational (consultative) character of this project aims to:

- provide further support for the water usage sector in Uzbekistan on all the levels of implementation (country, river basin, farming estates);

- increase social awareness on the sustainable use of water and other resources involved in agricultural production [23].

This programme aims to create a software product that contains the SUV-Info single reference database. The latter will be leveraged by the specialists in the sphere of water usage; reclamation and irrigation experts, associations of water users and farming estates to speed up hydraulic and other calculations, streamline the process of searching and obtaining information as well as distributing expertise related to all the aspects of control and usage of water resources.

The platform will improve the knowledge of stakeholders and organisations about technical aspects of controlling water resources. It will become a useful instrument for scientists, young specialists, and students of specialised universities. We expect that the creation of the reference database and the mobile application (for Android and iOS) will strengthen the scientific and educational programmes in the sphere of water usage. It will also help to modernise the educational facilities of colleges and universities.

The development of this system includes the creation of an innovative, modern, interactive environment based on modern technologies that will be available from any place via a web browser or through the most common mobile devices. The system will be available even in the regions with a limited speed of Internet connection.

In Russia, there are six main directions for the digital transformation of agriculture and the scientific and technical development of smart agriculture. These directions involve the adoption of not less than five projects of the full innovative complex scientific and technical cycle of end-to-end system classes: smart agricultural enterprise, smart field, smart farm, smart greenhouse, smart garden, smart land usage.

In its essence and target, the platform of the reclamative water usage industry belongs to the smart field class. This class aims to form the conditions for the development of scientific and technical activities as well as obtaining results for creating digital technologies of monitoring and controlling the production processes of crop farming in the field. The latter use Big Data technologies and the scientific theory of agricultural ecosystem productivity for obtaining products and providing services that ensure the independence and competitiveness of the national agricultural industry.
In the case of practical implementation of this digital platform, the digital product must go through significant stages of its development starting with the idea and product knowledge accumulation and finishing with its use in practice. Conceptually, these stages can be arranged in the following sequence:

- I - the stage of exploring and accumulating knowledge about a digital product;

- II - the stage of developing algorithms for the practical implementation of the product model;

- III - the stage of adopting the decision on whether this product is effective and feasible for practical use;

- IV - the stage of deploying the created product in production for verification

- $\mathrm{V}$ - the stage of using the product after acknowledging its practical value and effectiveness.

The practice of using IT in land reclamation shows the expansion in the number of tasks that can be solved with the help of computers. However, the most important task is still the formation of hydrotechnical systems for reclamation that provide the effective supply and discharge of water.

Nowadays, the technical level of reclamation systems allows for automating the process of water distribution from the source of irrigation to crops. However, not only the amount of water limits the growth and development of crops. These are also the number of nutrients, the heat and gas composition of the air in soils and near-soil level of the atmosphere, the pollution, and dehumification of soils, water erosion, etc. That's why it is necessary to create digital technologies to holistically control the recultivation regime in agricultural ecosystems including water, nutrition, heat, gas, and other regimes of lands and soils that form optimal conditions for growth and development of crops in predominant climate conditions in a particular year.

We suppose that research in the sphere of digital technologies for land reclamation will ensure the prioritised development of innovative systems for controlling agricultural production. These systems will manage the state of reclamation in agricultural systems on-line and will perform the intelligent processing of information, prepare final variants of decisions, and implement them while addressing the agricultural producers only in specified situations. The situation with the development, implementation, and usage of innovations in Russian agriculture is changing for better due to the development of precise land cultivation technologies in agricultural production. This establishes the relevance of research carried out by the specialists of the All-Russia Research Institute of Hydraulic Engineering and Reclamation by the name of A.N. Kostyakov. This work is carried out within the direction of establishing the feasibility of automating the control of the technological process for the formation of the reclamative state of agricultural ecosystems and the energetic potential of reclaimed lands that was part of the fundamental research plans of the institute in 2019 
The results of this research show that it is necessary to start solving the designated problems of digitalisation in the sphere of the reclamative water usage industry from creating commercial versions of automated systems for controlling the reclamation regime in agricultural ecosystems. The functional structure of these automated systems aims at the maximum automation of handling the data that characterise the formation of soil, the near soil level of atmosphere and the control of equipment that forms the recultivation regime of agricultural ecosystems according to the results of modelling agricultural production technologies at the level of field in the real time.

The practical solution of automating the precise control over the reclamation regime in the agricultural ecosystems and the fertility of reclaimed lands can be treated as an application for a corresponding digital platform that is integrated as a subplatform into the platform of the reclamative water usage industry. The latter can provide services for solving main production tasks in the sphere of agricultural reclamation based on smart field applications of the public-private digital agriculture platform.

The automatic control system for precise regulation of the reclamation regime in agricultural ecosystems that is offered for development is a structural element of the complex 'Digital platform for Russian agricultural industry'. In this respect, it should be integrated into the overall structure and should be related to other sub-platforms of the digital platform, the constituent parts of which must be compatible. While developing the approaches to the product for digitalising the control over reclaimed agricultural ecosystems, we used the field level logic of the reclamation industry. Thus, one of the possible directions for modernising the platform will be its enlargement to a higher level of organisation (plot, household, etc). The practical implementation and support of many necessary precise and balanced digital decisions in the agricultural industry on reclaimed lands will ensure not only the increase in its productivity but the implementation of the ecological constituent of highly intensive precise technologies that are the basis for the sustainable development of society.

The main results expected from the introduction of the digital platform for the reclaimed water usage industry is the increase in the productivity of field crop production by $20 \%$. This will be achieved by lowering the impact of factors limiting the productivity of plants, in particular by carrying out precise and scientifically based reclamation activities in specific conditions.

\section{CONCLUSION}

The specialised digital platform 'Reclaimed water usage industry' will allow for obtaining new control instruments by means of:

- reusing the information in the process of production and service provision;

- avoid limiting factors except for the size of the Internet;

- ensuring the competitiveness of a company independently of its size.
To bring the agricultural production on reclaimed lands to a new level of development using digital advances, it is necessary to have a combination of several prerequisites:

- the motivation of the state to develop digital technologies in agriculture;

- the presence of software shells for integrating the technological equipment, which is created in sufficient quantities and sufficient volumes, into end-to-end automated control technologies;

- the training of employees in sufficient quantities and with necessary skills.

\section{References}

[1] L.V. Kireicheva, O.A. Zakharova, "The effect of cyclic irrigation with wastewater on the properties of gray forest soils", Eurasian Soil Sci., vol. 35, no. 9, pp. 990-995, 2002.

[2] L.V. Kireicheva, O.B. Khokhlova, "Elemental composition of different fractions from the sapropel organic matter", Eurasian Soil Sci., vol. 33, no. 9, pp. 947-949, 2000.

[3] F.K. Abdrazakov, S.S. Orlova, T.A. Pankova, E.N. Mirkina, O.V. Mikheeva, "Risk assessment and the prediction of breakthrough wave during a dam accident", J. of Interdisciplinary Res., vol. 8, no. 1, pp. 154-161, 2018.

[4] V.I. Olgarenko, G.V. Olgarenko, I.V. Olgarenko, "A method of integral efficiency evaluation of water use on irrigation systems", Int. Multidisciplinary Sci., GeoConf. SGEM, vol. 18, no. 3.1, pp. 3-9, 2018.

[5] N. Fen, D.B. Kozlov, I.S. Rumyantsev, "Hydraulic studies of stepped spillways of various design", Power Technol. and Engineer., vol. 49, no. 5, pp. 337-344, 2016.

[6] N.F. Ryzhko, F.K. Abdrazakov, S.N. Ryzhko, S.V. Botov, "The increase of qualitative indicators during watering with multiple support sprinklers", J. of Fundamental and Appl. Sci., vol. 10, no. 6S, pp. 1482-1497, 2018

[7] M.A. Bandurin, V.A. Volosukhin, A.V. Mikheev, Y.V. Volosukhin, V.V. Vanzha, "Finite-element simulation of possible natural disasters on landfall dams with changes in climate and seismic conditions taken into account", J. of Phys.: Conf. Ser., vol. 1015, no. 032011, 2018.

[8] B.P. Chesnokov, O.V. Naumova, V.A. Strelnikov, F.K. Abdrazakov, B.A. Tronin "Polyethylene production from granules using high voltage", International Journal of Applied Engineering Research, vol. 11, pp. 2140-2144, 2016.

[9] V.I. Olgarenko, G.V. Olgarenko, I.V. Olgarenko, "Integrated assessment of the technical level of the irrigation and drainage systems", Meliorat. and water manag., vol. 6, pp. 8-11, 2013.

[10] D.V. Kozlov, A.N. Nasonov, I.M. Zhogin, I.V. Tsvetkov, "Multifractal principles of aquatic ecosystem development control by algacenosis correction", Water Res., vol. 44, no. 2, pp. 259-266, 2017.

[11] F.K. Abdrazakov, N.F. Ryzhko, S.N. Ryzhko, S.A. Horin, S.V. Botov, "Electricity consumption decrease at pump stations during watering by multi-support sprinkling units", J. of Fundam. and Appl. Sci., vol. 10, pp. 1464-1481, 2018.

[12] O.G. Degtyareva, D.A. Dac'o, G.V. Degtyarev, A. D. Gumbarov, "Design in cae system of low-head weir tiled foundation sinking", Proc. of the Kuban State Agrar. Univer., vol. 64, pp. 221-226, 2017.

[13] M.A. Bandurin, I.F. Yurchenko, I.P. Bandurina, "Computer Technology to Assess the Capacity Reserve of the Irrigation Facilities of the AgroIndustrial Complex" [2019 Int. Multi-Conf. on Industr. Engineer. and Modern Technol., no. 8933970, FarEastCon 2019].

[14] L.V. Kirejcheva, New technologies of designing, substantiation of construction, operation and management of land reclamation systems. Moscow: VNIIA, 2010, $240 \mathrm{p}$

[15] M.A. Bandurin, V.A. Volosukhin, I.F. Yurchenko, "Remote Monitoring of Reliability for Water Conveyance Hydraulic Structures", vol. 931, pp. 209-213, 2018 [Mater, Sci, Forum]. 
[16] O.G. Degtyareva, G.V. Degtyarev, N.L. Lavrov, D.U. Aliev, "Constructive-technological decisions in regulating the flow of atmospheric precipitation", Magazine of Civil Engineer., vol. 82, no. 6, pp. 32-48, 2018.

[17] M.A. Bandurin, I.F. Yurchenko, V.A. Volosukhin, V.V. Vanzha, Ya.V. Volosukhin, "Ecological and economic efficiency of diagnostics of technical condition of water supply facilities of irrigation systems", J. Ecol. and Industry of Russ., vol. 22, no. 7, pp. 66-71, 2018.

[18] L.V. Kireicheva, Scientific principles of creation and management of reclamation systems in Russia, 2017, pp. 296.

[19] O.G. Degtyareva, T.I. Safronova, I.I. Rudchenko, I.A. Prikhodko, "Nonlinearity account in the foundation soils when calculating the piled rafts of buildings and constructions", IOP Conf. Ser. Mater. Sci. and Engineer., vol. 698, no. 2, p. 022015, 2019.
[20] B.P. Chesnokov, O.V. Naumova, V.A. Strelnikov, F.K. Abdrazakov, B.A. Tronin, "Polyethylene production from granules using high voltage”, Int. J. of Appl. Engineer. Res., vol. 11, pp. 2140-2144, 2016.

[21] L.V. Kirejcheva, "New technologies for designing, substantiating the construction, operation and management of land reclamation systems", Under the scientific, p. 240, 2010.

[22] O. Degtyareva, G. Degtyarev, I. Togo, V. Terleev, A. Nikonorov, Yu. Volkova "Analysis of stress-strain state rainfall runoff control system - buttress dam", Procedia Engineering, vol. 165, pp. 1619-1628, 2016.

[23] V.G. Degtyarev, N.V. Kozhenko, "Consolidation processes in clay soils, taking into account the multistory building construction staging", IOP Conf. Ser. Mater. Sci. and Engineer., vol. 698, no. 2, p. 022016, 2019. 